\title{
Age Estimation from Pulp/Tooth Area Ratio in Three Mandibular Teeth by Panoramic Radiographs: Study of an Egyptian Sample
}

Mostafa M Afify ${ }^{1}$, Mohamed K Zayet ${ }^{2}$, Naglaa F Mahmoud ${ }^{3}$ and Ahmed R Ragab ${ }^{*}$

${ }^{1}$ Department of Forensic Medicine and Clinical Toxicology, Faculty of Medicine, Beni Suef University, Beni Suef, Egypt

${ }^{2}$ Department of Oral Radiology, Faculty of Oral and Dental Medicine, Cairo University, Cairo, Egypt

${ }^{3}$ Department of Forensic Medicine and Clinical Toxicology, Faculty of Medicine, Cairo University, Cairo, Egypt

${ }^{4}$ Department of Forensic Medicine and Clinical Toxicology, Faculty of Medicine, Mansoura University, Mansoura, Egypt

\begin{abstract}
Accurate age estimation of human adult is an important problem in both anthropological and forensic fields. Recently, determination of pulp/tooth area ratio from dental radiographs used as noninvasive and feasible methods for adult age prediction. The aim of this study was to test the reliability and applicability of pulp/tooth area ratio (PTR) in three mandibular teeth as an indicator of age by Panoramic Radiographs. A total of 500 panoramic radiographs of Egyptian individuals (262 males and 238 females), aged between 18 and 71 years, were studied. Pulp/tooth area ratios (PTR) were determined by AutoCAD 2010. Data were subjected to correlation and regression analysis which indicated that $2^{\text {nd }}$ premolar $\left(\mathrm{PM}_{2}\right)$ was the most closely correlated with age $(r=-0.947)$ followed closely by canine $(c)(r=-0.941)$. The $1^{\text {st }}$ premolar revealed the lowest correlation $(r=-0.914)$; among tooth combinations, the three teeth taken together had the best $R$ value (- 0.956). Linear regression equations were determined separately for the individual teeth and tooth combinations. The standard errors of estimates (S.E.E.) of the regression analyses for the individual teeth and tooth combinations ranged from \pm 4.10 to 5.66 years, indicating minimal difference in age estimates using solitary or multiple teeth. The observations obtained from the current study indicate that the PTR method is a useful procedure for assessing age with reasonable accuracy among Egyptians in forensic field.
\end{abstract}

Keywords: Age estimation; Pulp/tooth area ratio; Panoramic radiographs; Mandibular teeth; Egyptian

\section{Introduction}

Age estimation in adult is a fundamental question in forensic medicine. Although estimation of adult skeletal age at death is one of the most important identifying features in unknown individuals, it is also one of the most difficult to achieve [1,2]. However in the present global socio-political scenario, an increasing demand also exists for age estimation in living persons, such as immigrants, refugees, asylum Seekers (who seldom have any valid identification documents), to clarify criminal and civil liability and social issues $[3,4]$.

Teeth are the hardest part of the body and are least affected by the taphonomic process. They are considered as one of the reliable methods of identification of a person in forensic sciences [5]. A variety of methods are used for dental age estimation, for example, morphological, biochemical and histological methods [6,7]. However these methods are invasive and require tooth extraction, which is not possible in living individuals [8].

Non-invasive radiographic techniques have been developed for measurements of the reduction in the dental pulp cavity associated with advancing age due to secondary dentin formation $[9,10]$. This reduction in pulp chamber was correlated with chronological age and regression equations were derived to estimate the age $[11,12]$.

Since 2004, Cameriere et al. [13-16] have published several papers on a method of age estimation using the pulp/tooth area ratio to quantify the apposition of secondary dentine. The method has elicited more interest than others and has been tested on different teeth. Moreover, as stated be Babshet et al. [17] radiographic evaluation of secondary dentine may be the only non-invasive approach to estimate age from fully developed teeth. Hence, there may be few alternatives to dental age estimation of living adults as well as in certain postmortem circumstances wherein invasive methods are not feasible.

\section{Aim of the Work}

The aim of this study was to test the reliability and applicability of pulp/tooth area ratio (PTR) in three mandibular teeth as an indicator of age by Panoramic Radiographs.

\section{Subjects and Methods}

\section{Samples}

A total of 500 panoramic radiographs of Egyptian Subjects (262 males and 238 females), aged between 18 and 71 years were analyzed. These panoramic radiographs were undergone at the Oral Radiology Clinic, Faculty of Oral and Dental Medicine, Cairo University (Proline XC, Planmeca Oy - Helsinki, Finland). The exposure parameters were set according to the patient's age and size. The patient's identification number, sex, age and date of radiographic taking were recorded.

The inclusion and exclusion criteria were: Subjects should be clinically free from any developmental, endocrine or nutritional disorder and special dental diseases. Panoramic radiographs showing impacted teeth, teeth with root canal treatment, crown restorations, broken teeth, teeth with large areas of enamel overlap between neighboring teeth, missing one of the studied teeth or unclear radiographs were excluded from the study samples. All the three studied teeth, viz., mandibular canines (C), first premolars (PM1) and second premolars (PM2) were clearly visible. Protocols of the study and for radiographs collection of human subjects were approved by Ethical committee of Faculty of Oral and Dental Medicine, Cairo University

*Corresponding author: Ahmed Refat, Department of Forensic Medicine and Clinical Toxicology, Faculty of Medicine, Mansoura University, Mansoura, Egypt, Tel: 00966540990033; E-mail: ahmedrefat1973@yahoo.com

Received March 19, 2014; Accepted May 27, 2014; Published May 30, 2014

Citation: Afify MM, Zayet MK, Mahmoud NF, Ragab AR (2014) Age Estimation from Pulp/Tooth Area Ratio in Three Mandibular Teeth by Panoramic Radiographs: Study of an Egyptian Sample. J Forensic Res 5: 231 doi:10.4172/2157-7145.1000231

Copyright: @ 2014 Afify MM, et al. This is an open-access article distributed unde the terms of the Creative Commons Attribution License, which permits unrestricted use, distribution, and reproduction in any medium, provided the original author and source are credited. 
Citation: Afify MM, Zayet MK, Mahmoud NF, Ragab AR (2014) Age Estimation from Pulp/Tooth Area Ratio in Three Mandibular Teeth by Panoramic Radiographs: Study of an Egyptian Sample. J Forensic Res 5: 231 doi:10.4172/2157-7145.1000231

Page 2 of 5

\section{Measurements}

Measurements of the pulp and tooth areas were done according to Cameriere et al. [13-16]. Briefly, radiographs were saved as highresolution JPEG files on a computer and imported to AutoCAD 2010 software programme wherein the tooth's long axis was aligned vertically using the measure tool. Next, open the image file, enlarge the working area, and zoom in. A minimum of 20 points from each tooth outline and 10 points from each pulp outline has been identified and connected with the line tool on AutoCAD's Draw Toolbox. The pulp and tooth areas were measured using the point and line tools on the Draw toolbox and the pulp/tooth area ratio (PTR) calculated Figure 1.

All measurements were carried out by the same observer. Repeat measurements on 25 randomly selected radiographs were undertaken after an interval of two weeks and the values subjected to a paired t-test to assess potential intra- and inter-observer error. In the present study teeth were chosen either from the left or the right side, whichever were best suited for measurement. As according to Kvaal et al. [9], there are no significant differences between permanent teeth from the left and right side of the jaw.

\section{Statistical analysis}

Ratios derived from the various teeth were subjected to linear (single tooth) and multiple (tooth combinations) regression analysis using SPSS statistical package Version 20 (IBM Company, Chicago, IL). The regression correlation coefficients ( $r$ ) for single and multiple teeth were compared to ascertain which of them had a better relationship with age; as well as analysis of covariance (ANCOVA) to study the possible interaction between age \& sex and the three teeth. The S.E.E. was calculated to predict the deviation of the estimated age from the actual age which, in turn, reflects the accuracy of age prediction, as suggested by Liversidge et al. [18]. Linear regression equations were performed to calculate the regression equations following Cameriere et al. [19]. The intra- and inter-observer reproducibility were tested by paired Student t-test.

\section{Results}

The paired t-test to evaluate potential observer error revealed no statistically significant intra- and inter-observer differences between the paired sets of measurements carried out on the re-examined panoramic radiographs $(p>0.05)$. the measurements of the pulp/tooth area ratio of the tested teeth did not reveal any significant differences between men and women, and consequently sex was not included in the statistical models.

Age and sex distribution of individuals are listed in Table 1. The Descriptive statistics of pulp/tooth ratios of the three tested teeth were shown in Table 2.

The regression correlation coefficients, the standard errors of estimates (S.E.E.), and the regression equations derived for individual teeth as well as different tooth combinations are presented in Table 3. Among the teeth assessed, the $2^{\text {nd }}$ premolar $\left(\mathrm{PM}_{2}\right)$ was the most closely correlated with age( $\mathrm{r}=-0.947)$ followed closely by canine $(\mathrm{c})(\mathrm{r}=-0.941)$. The $1^{\text {st }}$ premolar revealed the lowest correlation $(\mathrm{r}=-0.914)$ Figure 2;

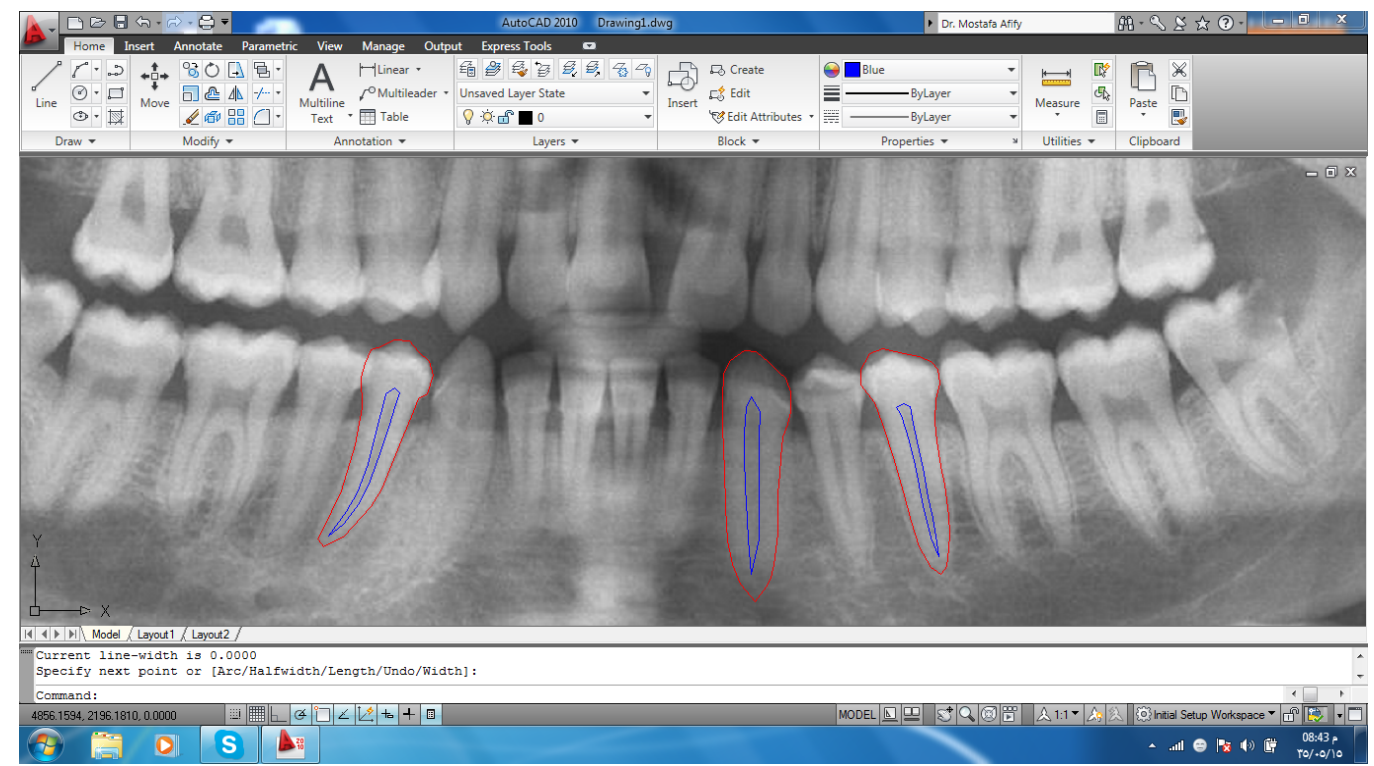

Figure 1: The canine, first premolar and second premolar as well as their pulp are shown delineated. This was accomplished first by defining the pulp and tooth outlines using the point and line tools on the AutoCad software program's Draw Toolbox; the areas of the outlined pulp and tooth were then calculated on the same software.

\begin{tabular}{|c|c|c|c|}
\hline Age-group (years) & Males & Females & Total \\
\hline $18-30$ & 92 & 116 & 208 \\
\hline $31-40$ & 66 & 46 & 112 \\
\hline $41-50$ & 54 & 34 & 88 \\
\hline $51-60$ & 34 & 30 & 64 \\
\hline $61-71$ & 16 & 12 & 28 \\
\hline Total & 262 & 238 & 500 \\
\hline
\end{tabular}

Table 1: Sample distribution across age-groups and sexes. 


\begin{tabular}{|c|c|c|c|c|}
\hline Tooth & Minimum & Maximum & Mean & No. SD \\
\hline Canine & 0.02 & 0.18 & 0.099 & 0.039 \\
\hline 1st premolar & 0.01 & 0.17 & 0.096 & 0.039 \\
\hline 2nd premolar & 0.02 & 0.18 & 0.097 & 500 \\
\hline
\end{tabular}

Table 2: Descriptive statistics of pulp/tooth ratios of the canine, $1^{\text {st }}$ premolar, $2^{\text {nd }}$ premolar Egyptian sample.

\begin{tabular}{|c|c|c|c|c|c|}
\hline Tooth & Regression equation & $\mathbf{r}$ & $\mathbf{R}^{2}$ & S.E.E & p-value \\
\hline Canine & $=69.6+(-332$ X PTR C) & -0.941 & $88.6 \%$ & 4.700 & 0.00 \\
\hline $1^{\text {st }}$ premolar & $=67.8+(-324 X$ PTR PM1 $)$ & -0.914 & $83.5 \%$ & 5.66 & 0.00 \\
\hline $2^{\text {nd }}$ premolar & $=69.2+(-336 \times$ PTR PM2 $)$ & -0.947 & $89.6 \%$ & 4.48 & 0.00 \\
\hline Canine $+1^{\text {st }}$ premolar & $=70.0+(-242$ X PTR C) + (-97.4X PTR PM1) & -0.947 & $89.6 \%$ & 4.49 & 0.00 \\
\hline Canine $+2^{\text {nd }}$ premolar & $=70.1+(-150$ X PTR C) $)+(-192 X$ PTR PM2 $)$ & -0.956 & $91.3 \%$ & 4.11 & 0.00 \\
\hline 1st premolar $+2^{\text {nd }}$ premolar & $=69.5+(-72.6 \times$ PTR PM1 $)+(-268 X$ PTR PM2 $)$ & -0.949 & $90.1 \%$ & 4.38 & 0.00 \\
\hline All three teeth & $=70.2+(-139 X$ PTR C) + ( -28.4X PTR PM1) + (-176 X PTR PM2) & -0.956 & $91.4 \%$ & 4.10 & 0.00 \\
\hline
\end{tabular}

Table 3: Regression coefficients and equations for the canine, $1^{\text {st }}$ premolar, $2^{\text {nd }}$ premolar, and various tooth combinations.

among tooth combinations, the three teeth taken together had the best $\mathrm{R}$ value (-0.956). Overall, all individual teeth/tooth combinations had high statistically significant correlation to age $(\mathrm{p}<0.01)$, Linear regression equations were determined separately for the individual teeth and tooth combinations. The standard errors of estimates (S.E.E.) of the regression analyses for the individual teeth and tooth combinations were found to be ranged from \pm 4.10 to 5.66 years Table 3 .

\section{Discussion}

Age estimation is a vital aspect in creating a biological profile of an individual. Dental age estimations of living adult individuals can be made using a verity of methods [7,20-23]. Age estimation by radiographic evaluation of secondary dentine deposition is an established non-invasive technique for adults [24]. Assessment of the pulp/tooth area ratio is an indirect quantification of secondary dentine deposition [25]. The ratio between pulp and tooth measurements was calculated and used in order to reduce the effect of any variation in the magnification or angulations of the radiographs [19]. In addition, earlier studies have indicated that the amount of secondary dentine is correlated with chronological age and can be measured indirectly by radiographs [9]. Consequently, evaluation of this parameter is considered as an "internal examination", with the potential to eliminate the effect of environmental factors on human remains [15].

However, the accuracy of these dental methods should be verified in different populations $[8,11,19,17]$. In Egypt, there are few studies in dental age estimation by pulp/tooth area ratio method in living adults. Therefore in the present study, the mandibular canine and premolars were analyzed to establish the patterns of the relationship between age and the apposition of secondary dentine in a contemporary Egyptian sample. Consequently, the reliability and applicability of pulp/tooth area ratio (PTR) as an age indicator of age was tested. The geometric factors of panoramic projection make the tracing of mandibular teeth easier than that of maxillary teeth. Among mandibular single-rooted teeth, canines were chosen for a number of reasons: they are often present in old age, they are less likely than other anterior teeth to suffer attrition or abrasion as a result of particular work, and they are the single root teeth with the largest pulp area and thus the easiest to analyze [19]. Other single-rooted teeth like lower premolars show good correlations between the decrease in dental pulp and increasing age [26]. Moreover, they are less liable to be traumatized unlike other single-rooted teeth namely, upper and lower incisors [27]. Panoramic radiographs were used in this study because of their advantages. It is not always possible to obtain periapical radiographs from three intact teeth for the purpose of age estimation, whereas access to panoramic radiographs is much more practical since they are taken for various purposes.

In this study, measurements of PTR show no statistically significant difference in male and female, this result runs in parallel with Previous studies $[19,28]$ on single-root teeth which shown that sex has no significant influence on age estimation. In addition, no statistically significant intra- and inter-observer differences between the paired sets of measurements carried out on the re-examined panoramic radiographs $(\mathrm{p}>0.05)$.

In the present study, multiple regression analysis, with age as dependent variable and pulp/tooth area ratio as predictor, yielded several formulae. A statistically significant correlation between age and PTR was found in the three mandibular teeth, the $2^{\text {nd }}$ premolar $\left(\mathrm{PM}_{2}\right)$ was the most closely correlated with age $(\mathrm{r}=-0.947)$ followed closely by canine $(\mathrm{C})(\mathrm{r}=-0.941)$, but the $1^{\text {st }}$ premolar revealed the lowest correlation $(\mathrm{r}=-\mathrm{0.914})$; among tooth combinations, the three teeth taken together had the best $\mathrm{R}$ value $(-0.956)$. These results are in agreement with Cameriere et al. [26], who utilized lower premolars panoramic radiographs of adult Spanish individuals and found that all correlations of PTR with age were significant. Also, these results are run parallel with Babshet et al. $[17,29]$ who reported low to moderate correlation between PTR of monoradicular teeth and chronological age by periapical digital radiographs for Indian. They attributed this low correlation to the rate of secondary dentine deposition may be relatively slow and irregularly paced in their population (Indians).

Cameriere et al. [16] believed that the size of the pulp area in canines revealed secondary dentinal deposition better than other teeth with smaller pulp areas (e.g., lateral incisor). In the present study, however, we revealed that the larger size of pulp areas of $2^{\text {nd }}$ premolar may lead to "more clear measurement" of the PTR. Taking multiple teeth did not markedly improve the PTR - age correlation when compared to single teeth (Table 3). This contrasts with the results of Camereiere et al. $[11,16]$ where the use of maxillary and mandibular canines, in combination, produced higher age correlation as well as more accurate age estimates when compared to those teeth taken alone. But these findings are similar to the results of Babshet et al. [29].

As regards regression analysis for age estimation from PTR, Linear regression equations were determined separately for the individual teeth and tooth combinations (Table 3). Obviously, the standard errors of estimates (S.E.E.) of the regression analyses for the individual teeth and tooth combinations ranged from ( \pm 4.10 to 5.66 years), indicating minimal difference in age estimates using solitary or multiple teeth. Unsurprisingly, there was little difference in S.E.E.s between the 

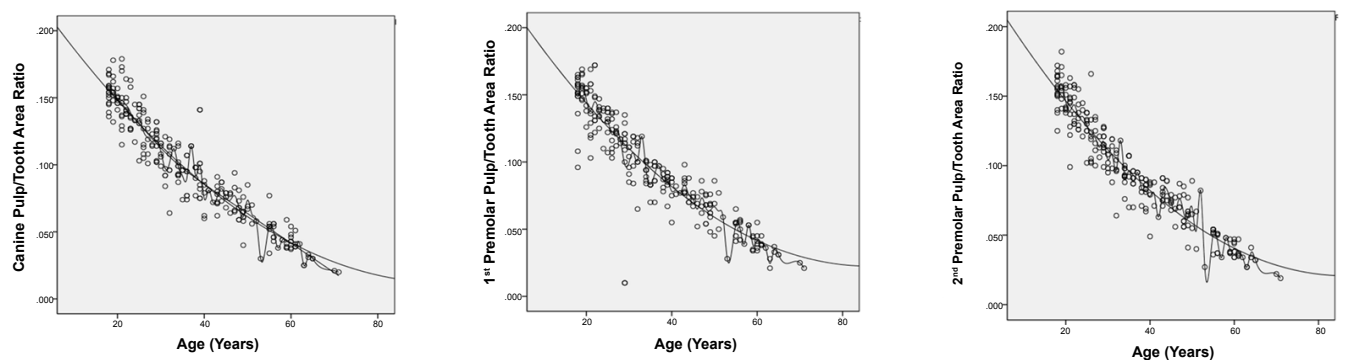

Figure 2: A scattered spot curve showing a significant indirect correlation between the age and Pulp/Tooth area ratio of the three studied teeth.

various linear and multiple regression equations. S.E.E. $< \pm 10$ years is considered acceptable in forensic age prediction [30]

These errors are similar to that obtained by Cameriere et al. [26] which ranged between 4.34 and 6.02 years for premolars. Also, compare to the results that obtained by Zaher et al. [31] who utilized periapical radiographs of maxillary incisors of adult Egyptian individuals was ranged between 1.2 to 5.08 years [31]. In addition to SEE of the present sample is slightly greater than those derived using single or multiple teeth in Cameriere et al. $[11,15,16,19]$ which ranged between approximately $\pm 2.5-5$ years. A possible reason for such low errors may be that they assessed teeth of the same class (i.e. maxillary and mandibular canines) and the radiographs obtained were taken particularly for these teeth (Periapical radiographs). In contrast, the teeth evaluated in our study belonged to multiple classes and, moreover, The main source of error in panoramic radiographs measurements seemed to be difficulties in identifying reference points on the radiographs when viewed on the monitor, and therefore in defining the line to be measured [12]. Many key factors which may influence these results must be also taken into account, such as individual variability of tooth size, variations in patterns of secondary dentine apposition and angles between X-ray beam and film. However, the results of this study showed a very high degree of intra-and inter-observer agreement, indicating high reproducibility of measurements.

\section{Conclusion}

In conclusion, our results of evaluation of the pulp/tooth area ratio of three mandibular teeth revealed that the $2^{\text {nd }}$ premolar had the highest correlation to age when used alone, followed by the canine and $1^{\text {st }}$ premolar. The use of these teeth in combinations slightly increases the correlation. Obviously, we have a low standard errors of estimates and there was little difference in S.E.E.s ( \pm 4.10 to 5.66 years) between the various linear and multiple regression equations. Consequently, this method showed promising results for dental age estimation by a non-invasive technique using dental radiographs, which will be suitable for forensic application among Egyptian population. Future research should aim at acquiring Periapical radiographs and use of different several teeth together, are recommended to improve the precision and reduce standard errors of age estimation in adult Egyptian individuals.

\section{References}

1. Cattaneo C, De Angelis D, Ruspa M, Gibelli D, Cameriere R, et al. (2008) How old am I? Age estimation in living adults: a case report. J Forensic Odontostomatol 26: 39-43.

2. Baccino $E$, Schmitt $A$ (2006) Determination of adult age at death in the forensic context. In: Schmitt A, Cunha E, Pinheiro J, editors. Forensic anthropology and medicine. New York: Humana Press : 259-280.

3. Schmeling A, Olze A, Reisinger W, König M, Geserick G (2003) Statistical analysis and verification of forensic age estimation of living persons in the
Institute of Legal Medicine of the Berlin University Hospital Charité. Leg Med (Tokyo) 5 Suppl 1: S367-371.

4. Black SM, Aggrawal A, Payne-James J (2010) Age Estimation in the Living: The Practi- tioners Guide, Wiley-Blackwell, West Sussex.

5. Gustafson G (1950) Age determination on teeth. J Am Dent Assoc 41: 45-54.

6. Ohtani S, Yamamoto $\mathrm{K}$ (1991) Age estimation using the racemization of amino acid in human dentin. J Forensic Sci 36: 792-800.

7. Takasaki T, Tsuji A, Ikeda N, Ohishi M (2003) Age estimation in dental pulp DNA based on human telomere shortening. Int J Legal Med 117: 232-234.

8. Meinl A, Tangl S, Pernicka E, Fenes C, Watzek G (2007) On the applicability of secondary dentin formation to radiological age estimation in young adults. $J$ Forensic Sci 52: 438-441.

9. Kvaal SI, Kolltveit KM, Thomsen IO, Solheim T (1995) Age estimation of adults from dental radiographs. Forensic Sci Int 74: 175-185.

10. Drusini AG, Toso O, Ranzato C (1997) The coronal pulp cavity index: a biomarker for age determination in human adults. Am J Phys Anthropol 103 353-363.

11. Cameriere R, Ferrante L, Belcastro GM, Bonfiglioli B, Rastelli E, et al. (2007) Age estimation by pulp/tooth ratio in canines by peri-apical X-rays. J Forensic Sci 52:166-170.

12. Bosmans N, Ann P, Aly M, Willems G (2005) The application of Kvaal's dental age calculation technique on panoramic dental radiographs. Forensic Sci Int 153: 208-212.

13. Cameriere R, Ferrante L, Cingolani M (2004) Variations in pulp/tooth area ratio as an indicator of age: a preliminary study. J Forensic Sci 49: 317-319.

14. Cameriere R, Ferrante L, Cingolani M (2004) Precision and reliability of pulp/ tooth area ratio (RA) of second molar as indicator of adult age. J Forensic Sci 49: 1319-1323.

15. Cameriere R, Brogi G, Ferrante L, Mirtella D, Vultaggio C et al (2006) Reliability in age determination by pulp/tooth ratio in upper canines in skeletal remains. J Forensic Sci 51: 861-864.

16. Cameriere R, Ferrante L, Belcastro MG, Bonfiglioli B, Rastelli E, et al. (2007) Age estimation by pulp/tooth ratio in canines by mesial and vestibular periapical X-rays. J Forensic Sci 52: 1151-1155.

17. Babshet M, Acharya AB, Naikmasur VG (2010) Age estimation in Indians from pulp/tooth area ratio of mandibular canines. Forensic Sci Int 197: 125

18. Liversidge HM, Lyons F, Hector MP (2003) The accuracy of three methods of age estimation using radiographic measurements of developing teeth. Forensic Sci Int 131: 22-29.

19. Cameriere R, Cunha E, Sassaroli E, Nuzzolese E, Ferrante L (2009) Age estimation by pulp/tooth area ratio in canines: study of a Portuguese sample to test Cameriere's method. Forensic Sci Int 193: 128.

20. Spalding KL, Buchholz BA, Bergman LE, Druid H, Frisén J (2005) Forensics: age written in teeth by nuclear tests. Nature 437 : 333-334.

21. Kagerer P, Grupe G (2001) Age-at-death diagnosis and determination of lifehistory parameters by incremental lines in human dental cementum as an identification aid. Forensic Sci Int 118: 75-82. 
Citation: Afify MM, Zayet MK, Mahmoud NF, Ragab AR (2014) Age Estimation from Pulp/Tooth Area Ratio in Three Mandibular Teeth by Panoramic Radiographs: Study of an Egyptian Sample. J Forensic Res 5: 231 doi:10.4172/2157-7145.1000231

Page 5 of 5

22. Ohtani S, Ito R, Yamamoto T (2003) Differences in the D/L aspartic acid ratios in dentin among different types of teeth from the same individual and estimated age. Int J Legal Med 117: 149-152.

23. Arany S, Ohtani S (2010) Age estimation by racemization method in teeth: application of aspartic acid, glutamate, and alanine. J Forensic Sci 55: 701-705.

24. Tavrianos C, Mastagas D, Stavrianou I, Karaiskou O (2008) Dental age estimation of adults: A review of methods and principals. Res $\mathrm{J}$ Med Sci 2: 258-268

25. Cunha E, Baccino E, Martrille L, Ramsthaler F, Prieto J, et al. (2009) The problem of aging human remains and living individuals: a review. Forensic Sci Int 193: 1-13.

26. Cameriere R, De Luca S, Alemán I, Ferrante L, Cingolani M (2012) Age estimation by pulp/tooth ratio in lower premolars by orthopantomography. Forensic Sci Int 214: 105-112.
27. Malikaew P, Watt RG, Sheiham A (2006) Prevalence and factors associated with traumatic dental injuries (TDI) to anterior teeth of 11-13 year old Thai children. Community Dent Health 23: 222-227.

28. Cameriere R (2008) Age Estimation project: Cameriere's methods for age estimation. Macerata (Italia): Eum, Edizioni Università di Macerata.

29. Babshet M, Acharya AB, Naikmasur VG (2011) Age estimation from pulp/ tooth area ratio (PTR) in an Indian sample: A preliminary comparison of three mandibular teeth used alone and in combination. J Forensic Leg Med 18: 350 354.

30. Solheim T, Sundnes PK (1980) Dental age estimation of Norwegian adults--a comparison of different methods. Forensic Sci Int 16: 7-17.

31. Zaher JF, Fawzy IA, Habib SR, Ali MM (2011) Age estimation from pulp/tooth area ratio in maxillary incisors among Egyptians using dental radiographic images. J Forensic Leg Med 18: 62-65. 